\title{
Textos multimodais na escola: estratégia para a produção escrita de minicontos
}

Julio César de Carvalho-Santos jucercarvalho@ hotmail.com Universidade de São Paulo (USP), São Paulo, São Paulo, Brasil.

\section{Felipe Mattei}

felipe.mattei@ hotmail.com

Campinas (PUC-Campinas), Campinas, São Paulo, Brasil.

\section{RESUMO}

Com o acesso cada vez mais intenso à internet, surgem gêneros textuais que começam a fazer parte da rotina dos alunos dessa geração. Desse modo, as aulas de língua portuguesa que não consideram essas práticas sociais contemporâneas de linguagem, por intermédio do âmbito virtual, podem não corresponder às escolhas de textos que os discentes elegem como mais interessantes, visto que, hoje cada vez mais leitores estão habituados a utilizarem a internet como suporte à leitura. Valendo desse princípio, além de poder utilizar esses textos como estratégia de leitura em sala de aula, a presente pesquisa tem como tema investigar como os gêneros veiculados na internet podem ser um instrumento em atividades de produção escrita. Para isso, optou-se em analisar minicontos, já que esse gênero é bastante comum em redes sociais, como o Facebook e o Twitter. O objetivo deste estudo visa apresentar minicontos como um exemplo de textos multimodais, dando ênfase à sua produção escrita a alunos do Ensino Fundamental.

PALAVRAS-CHAVE: Minicontos. Escrita. Sequência didática. Gêneros discursivos. Multiletramentos. 


\section{INTRODUÇÃO}

A tecnologia já faz parte do cotidiano de uma geração que busca rapidez nas informações e ao mesmo tempo entretenimento no uso das redes sociais. $\mathrm{Na}$ facilidade de acesso a um banco de conhecimento que transcende limites, os alunos são imersos em uma gama de recursos de linguagem, que de certo modo, busca atender a essa nova perspectiva de leitores.

A linguagem veiculada, nas redes sociais, visa resgatar essa lógica de leitura cujo objetivo denota emergir mais conteúdo ante a quantidade de linhas traçadas. No ambiente escolar, o professor de Língua Portuguesa enfrenta o desafio de ensinar a leitura e produção de textos convencionais. Contudo, assim como menciona Schneuwly e Dolz (2004), se o gênero sofre uma transformação, o comportamento dos interlocutores também se altera, portanto, uma adequação torna-se necessária para corresponder a evolução textual que emerge no ambiente digital.

Diante disso, a presente pesquisa tem como tema investigar a relevância da produção de gêneros veiculados na internet nas aulas de Língua Portuguesa, tendo como delimitação temática analisar minicontos, como uma atividade de produção textual. O objetivo deste estudo visa apresentar minicontos como um exemplo de textos multimodais, dando ênfase à sua produção escrita a alunos do Ensino Fundamental II.

Para atingir o objetivo proposto, inicialmente, apresenta-se o suporte teórico sobre letramento e o estudo da escrita, e posteriormente, destaca-se uma sequência didática que poderá vir de suporte para as produções textuais de minicontos em sala de aula.

\section{OS MINICONTOS COMO ATIVIDADE DE PRODUÇÃO ESCRITA EM GÊNEROS PRESENTES NA REDE VIRTUAL}

Santos (2016) buscou examinar o miniconto sob a perspectiva bakhtiniana de gênero discursivo, demonstrando como sua análise pode vir ao encontro de propostas de interpretação de texto em diversos níveis educacionais. Nessa proposta, objetivou-se em mensurar com são construídos os minicontos e sua finalidade comunicativa sob o olhar da leitura, assim como salienta o autor:

As temáticas propostas são influenciadas por diversos meios, sejam eles sociais, históricos, ou até mesmo convencionais de cunho bucólico ou amoroso. O que de fato desperta a criatividade proposta em seu contexto é despertar no leitor o uso de inferências e promover como propósito comunicativo uma leitura rápida, repleta de indícios ideológicos que influenciam o leitor tanto em sua capacidade de compreensão quanto em seu posicionamento. (SANTOS, 2016, p.12)

O desafio que agora se apresenta, é como utilizar o miniconto em propostas de produção textual, já que, conforme a Base Nacional Comum Curricular - BNCC, os minicontos foram incluídos como uma atividade de produção escrita para alunos do Ensino Fundamental II e são encontrados poucos materiais que trabalham com esse gênero sob o viés da escrita. 
(EF89LP35) Criar contos ou crônicas (em especial, líricas), crônicas visuais, minicontos, narrativas de aventura e de ficção científica, dentre outros, com temáticas próprias ao gênero, usando os conhecimentos sobre os constituintes estruturais e recursos expressivos típicos dos gêneros narrativos pretendidos, e, no caso de produção em grupo, ferramentas de escrita colaborativa. (BRASIL, 2018, p. 185)

Os minicontos são encontrados com mais facilidade em redes sociais como o Facebook e o Twitter, essas plataformas servem de veículo divulgador desse gênero e estão bem próximas do cenário de leitura em que os alunos do Ensino Fundamental se encontram habituados. Trazer esses veículos para a sala de aula podem estimular a produção desse gênero e direcionar com mais eficácia o trabalho pretendido. Perante isso, julga-se pertinente destacar que o uso dos minicontos poderá vir ao encontro como uma proposta de letramento em que sejam destacadas novas práticas sociais do uso da linguagem a partir da tecnologia.

De acordo com Rojo (2013), o letramento buscou reconhecer os valores culturais de determinados grupos e se formou o ideal de projetos (designers) para a obtenção de uma educação linguística adequada, por três dimensões: diversidade produtiva (trabalho); pluralismo cívico (cidadania) e identidades multifacetadas.

Em se tratando de diversidade produtiva, o cenário do trabalho visualiza uma nova concepção de mundo em que "espera-se um trabalhador multicapacitado e autônomo, flexível para adaptação à mudança constante" (ROJO, 2013, p.14). É fato que a tecnologia (instrumento que trouxe a praticidade das informações em tempo real) contribui muito para que a posição dos educadores seja composta por outra abordagem de letramento, já que as novas linguagens estão inseridas à realidade do educando e seria um desperdício desprezá-las.

O pluralismo cívico, por sua vez, permite aos alunos se expressarem e reconhecerem o mundo que o cercam, diante das variadas maneiras de manifestações de cultura, que se diferem por ter significações e valores provenientes de interesses diversificados.

Perante a um ensino fragmentado e descontextualizado, Rojo (2013) aborda a centralização do Estado como regulador, consoante a análise feita por Kalantzis e Cope. As ações governamentais padronizaram o ensino a partir da norma culta com suas regras e limitações. É visível que o ensino, ainda de certo modo, privilegie as nuances de um método desvinculado da vida social, desprezando as manifestações da oralidade. Apesar de a sociedade estar enraizada em outras composições de linguagem, isso ainda é ignorado pelo seu status de informalidade.

Ao se inserir um aprendizado que se distancie das composições tradicionais de letramento, o ensino fica subjugado a uma ação contraditória aos padrões, e de certo modo se exclui. Todavia, perante as inúmeras competências necessárias para que os alunos sejam engajados em diferentes diálogos, como apresentados por Kalantzis e Cope (1999, apud ROJO, 2013). A linguista salienta a importância dessa quebra de formalismo que implica: interagir com outras línguas e linguagens [...] criando sentido da multidão de dialetos, acentos, discursos, estilos e registros presentes na vida cotidiana, no mais pleno plurilinguismo bakhtiniano. (ROJO, 2013, p.17) 
À medida que os alunos estão ao redor de uma variedade de informações externas à escola, faz-se necessário haver uma interação com aquilo que o aluno tem contato no ambiente externo e a escrita ensinada. Isso justifica conhecimentos já permeados como os estudos de Vygotsky sobre a linguagem com influência do social e a perspectiva do conceito de enunciado por Bakhtin, em que cada enunciado é permeado por outros já vivenciados. O texto, a partir dessa diretiva, expõe a importância do hibridismo proveniente de outros gêneros de discurso presentes no cotidiano, sejam eles de caráter tecnológico ou dos diversos usos da linguagem.

Com o desenvolvimento da tecnologia, o texto obteve novos suportes, considerados mais interativos cujo posicionamento do leitor, em alguns casos, age em sincronia à produção do texto. Esses novos escritos expõem uma nova linhagem de gêneros discursivos que não são mais aprisionados somente à leitura do texto escrito, pois os recursos midiáticos e imagéticos colaboram nessa percepção de leitura interativa.

A partir do momento em que se padroniza o gênero, ele deixa de ser analisado pelo contexto e passa a ser compreendido por uma leitura fragmentada. Rojo (2013, p.22) esclarece a importância de avaliar o gênero diante do contexto em que está inserido, relatando que:

[...] as práticas de linguagem ou enunciações se dão sempre de maneira situada, isto é, em determinadas situações de enunciação ou de comunicação, que se definem pelo funcionamento de suas esferas ou campos de circulação de discursos (científico, jornalístico, literário, artístico, de entretenimento, íntimo, familiar e assim por diante). Essas esferas ou campos e seu funcionamento estão elas mesmas situadas historicamente, variando de acordo com o tempo histórico e as culturas locais (ou globais).

Ante os estudos realizados por Bakhtin (1981), atenta-se ao fato de que a língua é permeada por inúmeras influências do meio, consequentemente, o discurso passa a sofrer indícios cuja elaboração denuncia o perfil do usuário discursivo e sua relação com a linguagem. $\mathrm{O}$ autor, portanto, estabelece uma filosofia da linguagem, cujos valores permitem observar a linguagem como um meio de estabelecimento de teorias, envolvidas às questões do sujeito no mundo e sua interação no meio social.

O autor, também, evidencia o conceito de plurilinguismo presente no discurso que se refere à influência do contexto social, gêneros e modismo, por exemplo, como fator relevante que denuncia como a produção do discurso carrega variadas nuances na forma de estabelecer o processo comunicativo, deixando de lado apenas concepções puras da linguagem que tratam o discurso como um fato repleto de regras e sinalizações.

Assim sendo, o miniconto por ser um gênero que circula como bastante frequência na internet, torna-se um objeto de estudo interessante, pois é capaz de trazer para a sala de aula o contato com o ambiente virtual, e desse modo, promover práticas de uso da linguagem escrita que fazem parte da vivência do aluno. 


\section{O DESAFIO DA ESCRITA DE GÊNEROS VEICULADOS NA INTERNET}

Ensinar a escrever não é tarefa fácil. Muitos professores concordariam com essa afirmação, já que sabem o quanto é difícil fazer com que os alunos tenham interesse em produzir textos que não sejam específicos para habilidades exigidas no cotidiano. Fazer o aluno produzir uma dissertação como treino para um vestibular ou ensiná-lo a redigir um email, que ele poderá usar futuramente em seu trabalho, são tarefas mais fáceis de serem cumpridas.

Em se tratando de um gênero como o miniconto, pode-se até pensar que há uma determinada "facilidade" na aceitação em produzi-lo, pois trata-se de uma produção curta e que por ora pode ser vista como simplória. Contudo, o desafio de se escrever um miniconto não está no fato apenas de ser um texto curto, mas sim, poder escrever em poucas linhas um texto que possa ter sentido e criatividade.

Sendo assim, o papel do professor torna-se indispensável para que o aluno consiga trabalhar com o gênero, podendo compreender como a sua estrutura se forma, e ao mesmo tempo, ser capaz de mensurar a necessidade da escolha de um léxico e da organização sintática que se façam coerentes com a proposta textual, assim como mencionado por Klein (2007):

A partir, portanto, de uma compreensão histórica do homem, é possível afirmar que o contato com a criança e sua ação sobre os símbolos da escrita, ainda que esses símbolos estejam organizados correta e significativamente como linguagem, não garantem, por si sós, que a criança aprenda a linguagem escrita. Isso porque, nesta circunstância, o aprendiz estará diante de um punhado de "coisas" que não configuram a linguagem escrita. É preciso que haja homens utilizando a forma real e a linguagem para que ela se configure enquanto tal. (KLEIN, 1997, p. 99-100)

Além do desafio de incentivar os alunos a escreverem minicontos, é conveniente mencionar que os textos que são veiculados na internet são comumente escritos de maneira pouco convencional à gramática normativa e podem despertar o desinteresse dos professores quanto à sua utilização como mecanismo pedagógico, conforme abordado por Xavier (2005, p. 5), "As escolas, que desconhecem ou desconfiam do funcionamento e das vantagens das novas tecnologias, têm se recusado a usá-las em suas atividades cotidianas, e o que é pior, têm se deixado levar por ideias e concepções sem o menor fundamento científico".

A proposta aqui não é questionar o posicionamento da escola/educadores em relação a utilização dos gêneros textuais que estão presentes na internet quanto à sua produção gramatical escrita, o que de fato nos interessa é trazer esse gênero para a sala de aula e, a partir dessa inclusão como proposta de escrita, poder utilizá-lo como uma ferramenta de produção de texto. O que vale ressaltar é a necessidade de o professor mediar essa produção salientando a importância em se escrever, no ambiente escolar, a partir das concepções da gramática normativa, independentemente do suporte em que o gênero mais circule. 


\section{SEQUÊNCIA DIDÁTICA PARA PRODUÇÃO ESCRITA DO GÊNERO MINICONTO}

Para a elaboração de uma sequência didática em que o miniconto seja utilizado como uma ferramenta para a produção escrita, esta pesquisa utilizou-se dos critérios abordados por Heloísa Amaral, publicados no portal Escrevendo o Futuro. Desse modo, serão apresentadas nove etapas que servirão como base no processo de escrita, conforme a seguir:

Quadro 1: Sequência Didática para a produção escrita de gêneros textuais ${ }^{1}$
1. Apresentação da proposta
2. Partir do conhecimento prévio dos alunos
3. Contato inicial com o gênero textual em estudo
4. Produção do texto inicial
5. Ampliação do repertório sobre o gênero em estudo, por meio de leituras e análise de textos do gênero
6. Organização e sistematização do conhecimento sobre o gênero: estudo detalhado de sua situação de produção e circulação; estudo de elementos próprios da composição do gênero e de características da linguagem nele utilizada.
7. Produção coletiva
8. Produção individual
9. Revisão e reescrita

Fonte: Elaborado pelos autores

Antes de serem pedidas as produções textuais, é necessário que haja uma apresentação do gênero escolhido, ou seja, os alunos precisam conhecer o gênero que irão produzir antes mesmo que a produção, de fato, aconteça. Para isso, é prudente que sejam apresentadas algumas estratégias de leitura antes que se inicie a escrita, no intuito de efetivar a familiaridade com o texto.

Consoante Lopes-Rossi (2006), antes que sejam iniciadas as atividades de produção escrita, a autora sugere seis procedimentos que envolvem a leitura antecipada dos gêneros que forem trabalhados. Inicialmente, é necessário que sejam escolhidos um corpus para análise, nesse caso, recomenda-se que os minicontos sejam de acordo com a faixa etária da série em que se deseja trabalhar. Posteriormente, atenta-se as considerações sobre as condições de produção e circulação e as características composicionais (tabelas, gráficos, tipos de letras). Em seguida, os elementos verbais e não-verbais, as características linguísticas (construções frasais, escolha de léxico, etc.) e as marcas enunciativas (a imagem que o autor transmite pelo texto, a ideia apresentada, etc.).

Os quadros a seguir apresentam, a partir das considerações expostas por Lopes-Rossi (2006), como o gênero discursivo miniconto pode ser trabalhado sob a perspectiva de leitura em dois aspectos: sociocomunicativos e composicionais.

Quadro 2: Características do gênero discursivo miniconto

Recursos que possam ser ensinados sobre o gênero

Aspectos sociocomunicativos: condições de produção e circulação, finalidade comunicativa e temática. 


\begin{tabular}{|c|c|c|}
\hline$>$ & $\begin{array}{l}\text { Origem dos minicontos e } \\
\text { principais autores } \\
\text { brasileiros }\end{array}$ & $\begin{array}{l}\text { Dalton Trevisan na coletânea de Alfredo Bosi: O conto } \\
\text { brasileiro contemporâneo, década de } 70 \text {. Destaque } \\
\text { também para escritores como: Maria Lúcia Simões, } \\
\text { Contos contidos (1994); as narrativas de João Gilberto } \\
\text { Noll, Relâmpagos (1998); Luiz Arraes, A luz e a fresta } \\
\text { (1999) e Os cem menores contos brasileiros do século, } \\
\text { uma coletânea de minicontos elaborados por autores, } \\
\text { como: Millôr Fernandes, Moacyr Scliar, Manoel de Barros } \\
\text { e Dalton Trevisan, organizada por Marcelino Freire, em } \\
2004 \text { e Cem Toques Cravados de Edson Rossatto (2012). } \\
\text { Na internet, encontram-se diversas produções de autores } \\
\text { anônimos. }\end{array}$ \\
\hline$>$ & Veículos de circulação & $\begin{array}{l}\text { Os minicontos são veiculados em livros, contudo, se } \\
\text { tornaram mais populares a partir das produções } \\
\text { realizadas nas redes sociais, principalmente, no Facebook } \\
\text { e no Twitter. O Twitter, em especial, pela quantidade } \\
\text { reduzida de caracteres em suas postagens, se tornou o } \\
\text { suporte de maior circulação de minicontos da internet. }\end{array}$ \\
\hline & Finalidade comunicativa & $\begin{array}{l}\text { O propósito comunicativo desse gênero é entreter, fazer } \\
\text { o leitor refletir sobre o tema, despertar emoções a partir } \\
\text { de uma leitura concisa e significativa. }\end{array}$ \\
\hline & Definição de miniconto & $\begin{array}{l}\text { Em suma, trata-se de um texto que contenha poucos } \\
\text { caracteres e que seja capaz, apesar de sua estrutura } \\
\text { minimalista, de relatar uma breve história ou despertar } \\
\text { uma reflexão. }\end{array}$ \\
\hline & Tipologia textual & $\begin{array}{l}\text { O gênero miniconto, na grande maioria das vezes, se } \\
\text { apresenta como um texto narrativo, mas é possível } \\
\text { encontrar produções que se assemelhem com outras } \\
\text { formas de texto, como textos descritivos ou dissertativos. }\end{array}$ \\
\hline & Temáticas possíveis & $\begin{array}{l}\text { Traições, brigas, situações cômicas, crise conjugal, } \\
\text { conteúdos históricos, atualidades, problemas familiares, } \\
\text { crise econômica e política do Brasil, corrupção, etc. }\end{array}$ \\
\hline
\end{tabular}

Fonte: Elaborado pelos autores

Os aspectos sociocomunicativos são importantes para uma abordagem inicial sobre minicontos. Os alunos que já conhecem o gênero, por meio de suas redes sociais, desconhecem quando esse gênero surgiu, onde ele pode ser encontrado e quais as temáticas que podem ser abordadas, por exemplo. Desse modo, essa apresentação inicial poderá estimular a leitura dos minicontos não somente na internet, mas também, em produções de autores consagrados. 
Quadro 3: Aspectos linguísticos- textuais

Aspectos composicionais do miniconto

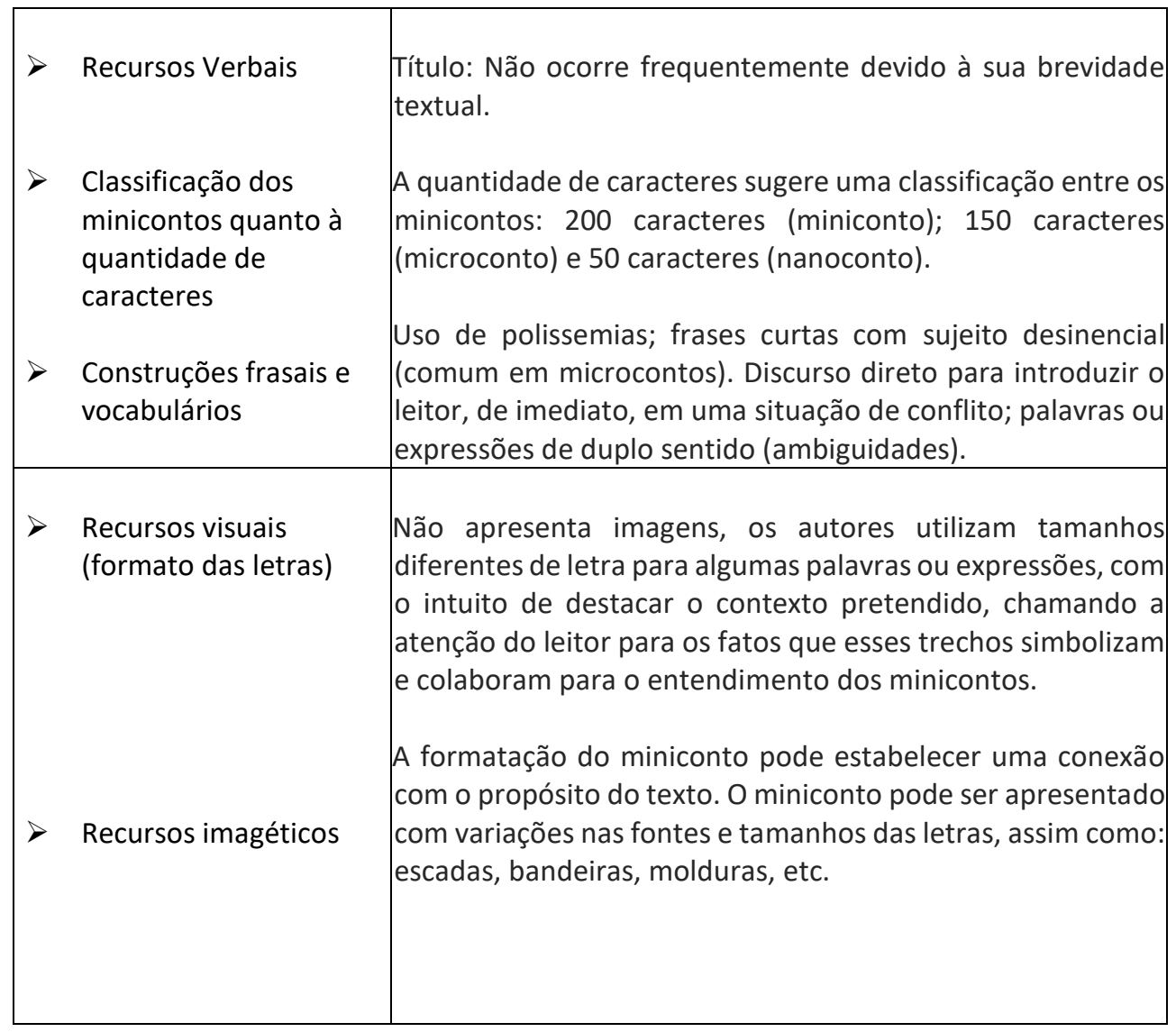

Fonte: Elaborado pelos autores

O professor, ao apresentar os aspectos composicionais do miniconto, permite que o aluno reconheça como esse gênero pode ser produzido. A escolha do léxico, as construções sintáticas e visuais são recursos que os minicontos apresentam e que precisam ser destacados nas aulas de leitura para que seja percebida a criatividade na construção do texto.

De volta à questão da escrita, exemplifica-se passo a passo cada item que corresponde a sequência didática apontada por Heloísa Amaral:

\section{1 - Apresentação da proposta}

Após a leitura detalhada de minicontos, o exercício de escrita precisa atender à faixa etária dos alunos envolvidos. Desse modo, a proposta sugerida é que os alunos produzam textos que façam referências a outros conhecidos, assim como a atividade que segue:

Escolha um conto de fadas ou uma história que seja bastante conhecida como referência ao seu miniconto. Lembre-se de destacar em seu texto um fato importante da história original para que o seu leitor possa entender a sua proposta. 


\section{Partir do conhecimento prévio dos alunos}

Atendendo a atividade exposta no item 1, o miniconto produzido por um aluno do 9o ano, elucida como é possível ter bons resultados quando o aluno, além de entender a proposta do texto, é capaz de referenciá-lo com outros que ele já conhece. Para um primeiro contato com o gênero, essa proposta pode ser o pontapé para produções futuras cada vez mais elaboradas.

Figura 1 - Miniconto produzido por aluno do 9o ano, atendendo a proposta sugerida no item 1

Ela correu pela escada, pois sabia que iria "esquecer" o sapatinho. Esperta, deixou que o bobão ficasse aos seus pés.

O miniconto produzido retrata de forma irônica uma passagem do conto Cinderela, em que a personagem, com medo do relógio bater à meia-noite, corre pelas escadas do palácio e acaba por perder um de seus sapatinhos. Contudo, na visão do autor, a garota tinha uma segunda intenção em esquecê-lo, o que ela fez foi intencional, pois de algum modo sabia que o príncipe iria encontrá-la.

Os procedimentos seguintes, especificamente 3, 5 e 6 referem-se à leitura: Contato inicial com o gênero textual em estudo; Ampliação do repertório sobre o gênero em estudo, por meio de leituras e análise de textos do gênero e organização e sistematização do conhecimento sobre o gênero: estudo detalhado de sua situação de produção e circulação; estudo de elementos próprios da composição do gênero e de características da linguagem nele utilizada. Essas etapas serão realizadas, inicialmente, à produção do texto escrito, todavia, tornase prudente repeti-las após a produção inicial que se refere ao procedimento 4 . 0 aluno, após esse primeiro contato com a produção escrita, a partir das percepções de como o gênero é produzido, terá mais facilidade de reescrever ou adaptar o seu texto às características do gênero.

Os três últimos procedimentos referem-se à produção coletiva, produção individual e revisão e reescrita. A produção coletiva é uma modalidade de escrita interessante, principalmente, quando se começa a trabalhar com um gênero discursivo pouco divulgado nas escolas, como o miniconto. Nessa proposta de produção, o aluno poderá compartilhar suas ideias com a classe, permitindo que haja interação e discussão sobre os temas que podem vir a ser escolhidos para a produção dos textos individuais.

A revisão e a reescrita são passos fundamentais para a concretização do trabalho com a produção de texto, quando se permite ao aluno rever o texto produzido, por meio dos comentários de correção, e a partir daí produzir uma versão final escrita, a possibilidade de haver êxito nesse processo-aprendizagem torna-se mais evidente, devido à maturidade que o educando vai atingindo com o procedimento de reescrita, assim como aponta Menegassi (2000, p. 84):

O processo de revisar a partir dos comentários do professor pode desencadear novas ideias que contribuem para a construção do texto, 
original, uma vez que, a cada nova experiência em sua vida, o texto acumula informações que o fazem crescer; consequentemente, alterará o seu texto em construção.

Cada etapa desse processo de construção de um texto dependerá obviamente do cenário educacional de cada escola, contudo, as sugestões apresentadas nesta pesquisa podem ser norteadoras para a elaboração de atividades de escrita de minicontos ou até mesmos de outros gêneros. $\mathrm{O}$ que se deve levar em consideração é o cuidado com a inserção do gênero e conhecer o repertório de cada público, para que essa atividade, conforme dito, faça parte do repertório do aluno. 


\title{
Textos multimodais na escola: estratégias para a produção escrita de minicontos
}

\begin{abstract}
With the increasingly access to the Internet, textual genres are emerging to be part of students routine of this generation. Thus, Portuguese language classes that do not consider these contemporary social practices of language, through the virtual context, may not correspond to the texts choices that students prefer as more interesting, since, today, more and more readers are accustomed to Internet like a support reading. Based on this principle, besides using these texts as a strategy of reading in the classroom, the present article try to investigate how the genres transmitted on the Internet can be an instrument in written production activities. For this, it was decided to analyze flash fictions, since this genre is quite common in social networks, like Facebook and Twitter. The objective of this study is to present flash fictions as an example of multimodal texts, emphasizing its written production to Elementary School Students.
\end{abstract}

KEYWORDS: Flash Fictions. Writing. Following teaching. Discursive genres. Multiliteracies. 
${ }^{1}$ Disponível em:

https://www.escrevendoofuturo.org.br/conteudo/biblioteca/nossaspublicacoes/revista/artigos/artigo/1539/sequencia-didatica-e-ensino-degeneros-textuais

\section{REFERÊNCIAS}

BAKHTIN, Mikhail. Marxismo e filosofia da linguagem. 2. ed. São Paulo: Hucitec, 1981.

BRASIL. Ministério da Educação. Base Nacional Comum Curricular BNCC. Brasília, DF, 2018.

KLEIN, Lígia Regina. Alfabetização: quem tem medo de ensinar? São Paulo/Campo Grande: Cortez/Editora da Universidade Federal do Mato Grosso do Sul, 1997.

MENEGASSI, José Renilson. Comentários de revisão na reescrita de textos. Trabalhos em Linguística Aplicada, v.35. Campinas, 2000. P.83-93.

ROJO, Roxane. Gêneros discursivos do Círculo de Bakhtin e multiletramentos. In. ROJO, R. (Org.) Escola conectada: os multiletramentos e as TICs. São Paulo: Parábola, 2013, p. 13-36.

SANTOS, Júlio César de. O gênero miniconto por uma perspectiva bakhtiniana. Pesquisas em Discurso Pedagógico, v.2. Rio de Janeiro: PUC - RJ, 2016.

SCHNEUWLY, Bernard; DOLZ, Joaquim. Os gêneros escolares: das práticas de linguagem aos objetos de ensino. In: SCHNEUWLY, B.; DOLZ, J. Gêneros orais e escritos na escola. Campinas: Mercado de Letras, 2004. p. 71-91.

XAVIER, Antônio Carlos. Reflexões em torno da escrita nos novos gêneros digitais da internet. Revista Investigações, v.18, n.2. Recife: Universidade Federal de Pernambuco, 2005. 
Recebido: 20 jan. 2019

Aprovado: 20 mar. 2020

DOI: $10.3895 /$ rl.v22n36.9377

Como citar: CARVALHO-SANTOS, Júlio Cesar de; MATTEI, Felipe. Textos multimodais na escola: estratégias para a produção e escrita de minicontos. R. Letras, Curitiba, v. 22, n. 36 p. 101-113, mar. 2020. Disponível em: $<$ https://periodicos.utfpr.edu.br/rl>. Acesso em: XXX

Direito autoral: Este artigo está licenciado sob os termos da Licença Creative Commons-Atribuição 4.0 Internacional.

(c) (1) 